\title{
Radical penectomy, a compromise for life: results from the PECAD study
}

\author{
Jamil Ghahhari ${ }^{1}$, Michele Marchioni ${ }^{2}$, Philippe E. Spiess ${ }^{3}$, Juan J. Chipollini ${ }^{3}$, Peter Nyirády ${ }^{4}$, Judith Varga ${ }^{4}$, \\ Pasquale Ditonno $^{5}$, Stefano Boccasile ${ }^{5}$, Giulia Primiceri ${ }^{2}$, Cosimo De Nunzio ${ }^{1}$, Giorgia Tema ${ }^{1}$, \\ Andrea Tubaro ${ }^{1}$, Alessandro Veccia ${ }^{6}$, Alessandro Antonelli ${ }^{6}$, Gennaro Musi ${ }^{7}$, Ottavio De Cobelli ${ }^{7}$, \\ Andrea Conti ${ }^{7}$, Stefano Puliatti ${ }^{8}$, Salvatore Micali ${ }^{8}$, Mario Álvarez-Maestro ${ }^{9}$, José Quesada Olarte ${ }^{9}$, \\ Erico Diogenes ${ }^{10}$, Marcos Venicio Alves Lima ${ }^{10}$, Andrew Tracey ${ }^{11}$, Georgi Guruli ${ }^{12}$, Riccardo Autorino ${ }^{11}$, \\ Petros Sountoulides $^{12}$, Roman Sosnowski ${ }^{13}$, Luigi Schips ${ }^{2}$, Luca Cindolo ${ }^{14}$
}

${ }^{1}$ Department of Urology, Hospital “Sant'Andrea”, Sapienza University, Roma, Italy; 'Department of Urology, “G.D’Annunzio” University, Chieti, Italy; ${ }^{3}$ Department of Genitourinary Oncology, Moffitt Cancer Center, Tampa, FL, USA; ${ }^{4}$ Department of Urology, Hospital of Budapest, Budapest, Hungary; ${ }^{5}$ Department of Emergency and Organ Transplantation, Urology and Andrology Unit II, University of Bari, Bari, Italy; ${ }^{6}$ Department of Urology, Hospital "Spedali Civili”, Brescia, Italy; ${ }^{7}$ Department of Urology, Istituto Europeo di Oncologia, University of Milan, Milan, Italy; ${ }^{8}$ Department of Urology, University of Modena \& Reggio Emilia, Modena, Italy; ${ }^{9}$ Department of Urology, Hospital Universitario La Paz, Madrid, Spain; ${ }^{10}$ Department of Urology, Ceara Cancer Institute, Fortaleza, Brazil; ${ }^{11}$ Department of Urology, Virginia Commonwealth University, Richmond, VA, USA; ${ }^{12} 1$ st Urology Department Aristotle University of Thessaloniki, Thessaloniki, Greece; ${ }^{13}$ Department of Uro-Oncology, Maria SkłodowskaCurie Memorial Cancer Center, Warsaw, Poland; ${ }^{14}$ Department of Urology, ASL 2 Abruzzo, Hospital "S. Pio da Pietrelcina”, Vasto, Italy Contributions: (I) Conception and design: L Cindolo, J Ghahhari, M Marchioni; (II) Administrative support: None; (III) Provision of study materials or patients: All authors; (IV) Collection and assembly of data: L Cindolo, J Ghahhari, M Marchioni; (V) Data analysis and interpretation: M Marchioni, L Cindolo, J Ghahhari; (VI) Manuscript writing: All authors; (VII) Final approval of manuscript: All authors.

Correspondence to: Jamil Ghahhari. Urology Resident, Department of Urology, Hospital “Sant'Andrea”, Sapienza University, Roma, Italy. Email: jamil.ghahhari@gmail.com.

Background: The use of organ sparing strategies to treat penile cancer (PC) is currently supported by evidence that has indicated the safety, efficacy and benefit of this surgery. However, radical penectomy still represents up to $15-20 \%$ of primary tumor treatments in PC patients. The aim of the study was to evaluate efficacy in terms of overall survival (OS) and disease-free survival (DFS) of radical penectomy in PC patients. Methods: Data from a retrospective multicenter study (PEnile Cancer ADherence study, PECAD Study) on PC patients treated at 13 European and American urological centers (Hospital "Sant'Andrea", Sapienza University, Roma, Italy; "G.D’Annunzio" University, Chieti and ASL 2 Abruzzo, Hospital "S. Pio da Pietrelcina”, Vasto, Italy; Department of Genitourinary Oncology, Moffitt Cancer Center, Tampa, FL, USA; Hospital of Budapest, Hungary; Department of Emergency and Organ Transplantation, Urology and Andrology Unit II, University of Bari, Italy; Hospital "Spedali Civili”, Brescia, Italy; Istituto Europeo di Oncologia, University of Milan, Milan, Italy; University of Modena \& Reggio Emilia, Modena, Italy; Hospital Universitario La Paz, Madrid, Spain; Ceara Cancer Institute, Fortaleza, Brazil; Virginia Commonwealth University, Richmond, VA, USA; Aristotle University of Thessaloniki, Thessaloniki, Greece; Maria Skłodowska-Curie Memorial Cancer Center, Warsaw, Poland) between 2010 and 2016 were used. Medical records of patients who specifically underwent radical penectomy were reviewed to identify main clinical and pathological variables. Kaplan-Meier method was used to estimate 1- and 5-year OS and DFS.

Results: Of the entire cohort of 425 patients, 72 patients $(16.9 \%)$ treated with radical penectomy were extracted and were considered for the analysis. The median age was 64.5 (IQR, 57.5-73.2) years. Of all, 41 (56.9\%) patients had pT3/pT4 and 31 (43.1\%) pT1/pT2. Moreover, 36 (50.0\%) were classified as pN1-3 and $5(6.9 \%)$ M1. Furthermore, $61(84.7 \%)$ had a high grade (G2-G3) with $6(8.3 \%)$ positive surgical margins. The 1 - and 5-year OS rates were respectively $73.3 \%$ and $59.9 \%$, while the $1-$ and 5 -year DFS rates were respectively $67.3 \%$ and $35.1 \%$. 
Conclusions: PC is an aggressive cancer particularly in more advanced stage. Overall, more than a third of patients do not survive at 5 years and more than $60 \%$ report a disease recurrence, despite the use of a radical treatment.

Keywords: Penile cancer (PC); radical penectomy; penile amputation; European Association of Urology guidelines (EAU guidelines); lymphadenectomy; survival; organ sparing surgery (OSS)

Submitted Oct 17, 2019. Accepted for publication Mar 12, 2020.

doi: $10.21037 /$ tau.2020.04.04

View this article at: http://dx.doi.org/10.21037/tau.2020.04.04

\section{Introduction}

Penile cancer (PC) and its most common histopathological subtype, squamous cell carcinoma (SCC), are uncommon neoplasms in developed nations, ranging from 0.6 to 6.8 per 100,000 men $(1,2)$, accounting for an estimated $0.2-0.4 \%$ of malignancies in men (1-5). Notwithstanding its low incidence, this cancer was diagnosed in 2018, in the United States, in more than 2,000 patients and was the cause of death in approximately 400 deaths $(6,7)$.

This neoplasia when diagnosed could require aggressive treatment resulting in significant morbidity, with negative impact on quality of life, including its devastating role on the psychology and sexuality of patients (8-10).

Age at diagnosis, stage, histologic grade and subtype of the tumor, presence of perineural and lymphatic infiltration, lymph node $(\mathrm{LN})$ involvement are considered prognosiskey issues $(11,12)$.

The gold standard treatment for localized PC is surgery. Although in the case of premalignant conditions or PC early stages an organ sparing surgery (OSS) (glans resurfacing, laser ablation, topical agents, i.e., 5-fluorouracil and imiquimod, glansectomy, local excision) may be applicable, partial or radical/total penectomy with perineal urethrostomy combined with radical inguinal lymphadenectomy still remains the recommended option for locally advanced and advanced invasive disease (11,13-17).

The OSS is undoubtedly an attractive option, but is still underused because of a presumed high risk of local recurrence $(18,19)$. Mossanen et al. questioned the use of radical penectomy for optimal oncological control supporting the idea that partial penectomy may ensure overlapping survival rates to radical approach (20). Moreover, Chipollini et al. focused on the need of an appropriate follow up program in patients of pT2 tumor treated with OSS (21). Despite general interest for expanding indications of OSS, radical penectomy still represents up to $15-33 \%$ of treatments offered to PC patients (18,22-24).

Due to the rarity of PC, without level 1 evidence, in the absence of prospective and randomized studies to guide decision making, it is difficult to exactly define the oncology efficacy of one surgical option over the others.

The objective of this retrospective multi-institutional international study is to present our overall experience with radical penectomy for SCC.

\section{Methods}

\section{Study population and main characteristics of interest}

Following approval by the local ethical committees we retrospectively reviewed the clinical notes of all patients with PC that underwent surgical treatment in 13 European and American Centers from 2010 to 2016 (Penile Cancer Adherence study, PECAD Study). Demographics, patient's comorbidities, history of circumcision, site and size of the primary lesion and primary local therapy, LN management and histopathology data were collected and analyzed. The type of surgical procedure was decided upon after taking into consideration surgeon's and patient's preferences and the European Association of Urology (EAU) Guidelines on PC. No perioperative chemotherapy or postoperative radiation was used for the management of the penile lesions. Staging was performed using physical examination and cross-sectional imaging with computed tomography (CT) and/or magnetic resonance imaging (MRI). Histopathological reports were provided by local genitourinary pathologists and according to local institutional protocol and the American Joint Committee on Cancer (AJCC)/International Union Against Cancer (UICC) 2009 TNM Classification for stage and grade. Only SCC cases were considered. Follow-up was done with periodical physical examination and imaging according to 
Table 1 Descriptive characteristics of the included patients

\begin{tabular}{|c|c|}
\hline Variable & Value, median (IQR) or $n(\%)$ \\
\hline Age & 64.5 (57.5-73.2) \\
\hline Follow up & $11.7(8.2-25.6)$ \\
\hline Circumcision & $31(43.1)$ \\
\hline Diabetes & $6(8.3)$ \\
\hline Hypertension & $17(23.6)$ \\
\hline Cardiovascular disease & $6(8.3)$ \\
\hline Dyslipidemia & $3(4.2)$ \\
\hline Obesity & $7(9.7)$ \\
\hline \multicolumn{2}{|l|}{ Site } \\
\hline Foreskin & $1(1.4)$ \\
\hline Glands & $32(44.4)$ \\
\hline Both & $39(54.2)$ \\
\hline Positive clinical node & $40(55.6)$ \\
\hline \multicolumn{2}{|l|}{ T-stage } \\
\hline $\mathrm{pT} 1 / 2$ & $31(43.1)$ \\
\hline $\mathrm{pT} / 4$ & $41(56.9)$ \\
\hline \multicolumn{2}{|l|}{$\mathrm{N}$-stage } \\
\hline pNO & $14(19.4)$ \\
\hline $\mathrm{pN} 1$ & $10(13.9)$ \\
\hline pN2 & $19(26.4)$ \\
\hline pN3 & $7(9.7)$ \\
\hline $\mathrm{pNx}$ & $22(30.6)$ \\
\hline \multicolumn{2}{|l|}{ M-stage } \\
\hline MO & $48(66.7)$ \\
\hline M1 & $5(6.9)$ \\
\hline $\mathrm{Mx}$ & $19(26.4)$ \\
\hline \multicolumn{2}{|l|}{ Grade } \\
\hline G1 & $11(15.3)$ \\
\hline G2 & $43(59.7)$ \\
\hline G3 & $18(25)$ \\
\hline Positive margins & $6(8.3)$ \\
\hline Vascular invasion & 24 (33.3) \\
\hline Lymphovascular invasion & $25(34.7)$ \\
\hline Lymphadenectomy & $51(70.8)$ \\
\hline
\end{tabular}

$I Q R$, interquartile range. stage and risk stratification for all patients

\section{Survival endpoints}

The main survival endpoint of the study was to describe disease-free survival (DFS) rates. Secondary endpoint was to describe overall survival (OS). We defined follow-up as the time interval between surgery and disease recurrence or death for any cause. For patients in whom none of the events occurred, we defined the follow-up time interval as the period from surgery to the last follow-up visit.

\section{Statistical analysis}

Descriptive statistics relied on median and interquartile range (IQR) to summarize quantitative data, while frequency and proportions summarized qualitative data. Kaplan-Meier method was used to estimate DFS and OS rates at 1 and 5 years. Cox proportional hazards model were used to estimate the hazard ratios of main predictors of disease recurrence.

All statistical analyses were performed using R Statistical Software (version 3.5.3; R Foundation for Statistical Computing, Vienna, Austria). All tests were two-tailed, and a $\mathrm{P}$ value $<0.05$ was considered indicative of a statistically significant association.

\section{Results}

The PECAD registry included 481 patients. Of all 84 (17.4\%) underwent radical penectomy. After applying inclusion and exclusion criteria, 72 patients were retained in the study cohort (we excluded those on whom we had no information on the grade of the tumor or lost on followup). The median age was 64.5 (IQR, 57.5-73.2) years. Of all, $43.1 \%$ were circumcised, approximately half of the patients had tumors localized both to the foreskin and glands $(54.2 \%)$, while none of them had tumors located in the shaft (Table 1).

Moreover, just over half of patients harbored pT3/ pT4 stages $(56.9 \%)$. At presentation $55.6 \%$ of patients had palpable inguinal LN. Inguinal lymph node dissection (LND) was performed in $51(70.8 \%)$ patients (with adherence to the EAU guidelines of $97 \%$ ). One third of the patients who underwent LND harbored $\mathrm{pN} 2$ stage (30.0\%).

At a median follow up of 11.7 months (IQR, 8.2-25.6), $29(40.3 \%)$ patients experienced disease recurrence. Among them $11(15.3 \%)$ local and $14(19.4 \%)$ had a systemic 

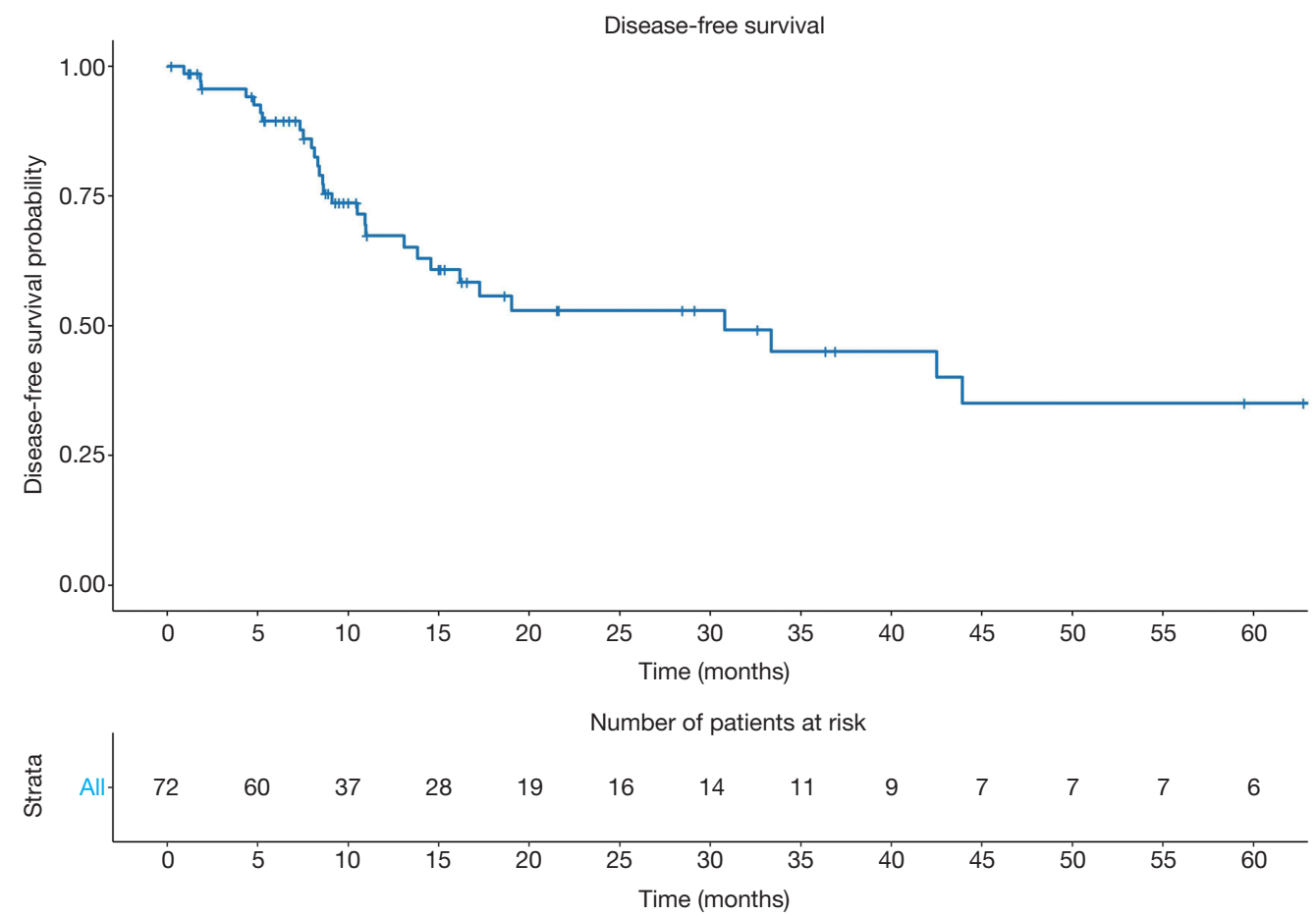

Figure 1 Disease-free survival in the study population.

recurrence. Thirteen (18.1\%) patients underwent an adjuvant chemotherapy cycle while seven patients $(9.7 \%)$ continued therapeutic plan with subsequent radiotherapy.

The 1 - and 5 -year DFS rates were $67.3 \% \pm 6.3 \%$ and $35.1 \% \pm 8.8 \%$, respectively (Figure 1 ). In univariable analyses the only predictor of disease recurrence was the $\mathrm{pN}$ stage. Indeed, higher recurrence rates were recorded in $\mathrm{pN} 2$ [hazard ratio (HR): $3.5,95 \%$ confidence interval (CI): 1.07-11.39, $\mathrm{P}=0.038$ ] and $\mathrm{pN} 3$ (HR: 4.22, 95\% CI: 1.04 17.12; $\mathrm{P}=0.043)$ patients, compared their $\mathrm{pN} 0$ counterpart. Overall, $19(26.4 \%)$ patients died. The 5 -year OS rates were $59.9 \% \pm 7.9 \%$ (Figure 2).

\section{Discussion}

The radical surgical approach in PC has historically been considered the gold standard in the subgroup of patients at intermediate and high risk (anatomical-pathological stage $\geq \mathrm{pT} 1$ ) with it a not indifferent "baggage" in terms of mortality, morbidity, physical, psychological and sexual impact. This therapeutic choice is emerging, evaluating data available in the literature, as the first indication furthermore in a significant percentage of subjects classified as low grade, early stage or in case of precancerous lesions, therefore in a subset of possible candidates for a less mutilating and less aggressive approach such us organ-sparing surgery (OSS). Radical treatment option is going to represent therefore, up to $30 \%$ to date, particularly in non-reference centers, with low volume of $\mathrm{PC}$ patients $(18,22-24)$. In recent years, therefore, it is not surprising that more and more interests and attentions have focused around the OSS of PC with all his arrows and weapons, ranging from laser therapy with neodymium-doped yttrium aluminum garnet or carbon dioxide mediums to OSS like Mohs surgery, circumcision, glansectomy, glans resurfacing or partial penectomy approach trying to expand the therapeutic window more and more in favor of this preservation techniques $(18,21,25,26)$.

In our study we exported, from the total pool present in a larger database which counts 425 total subjects diagnosed with PC, the data of 72 patients treated in the first instance with radical surgery. Our work aimed at evaluating the effectiveness in terms of OS and DFS at 1 and 5 years, focusing on an average follow-up period of 11.7 months. Our data has exposed the aggressiveness and poor prognosis of this neoplasm, despite the use of a radical approach. The OS rate was only slightly higher than $59 \%$ at 5 years, with a 5 -year DFS rate of just $35 \%$. These results are in agreement with what reported by the current literature. Zhu et al. in 

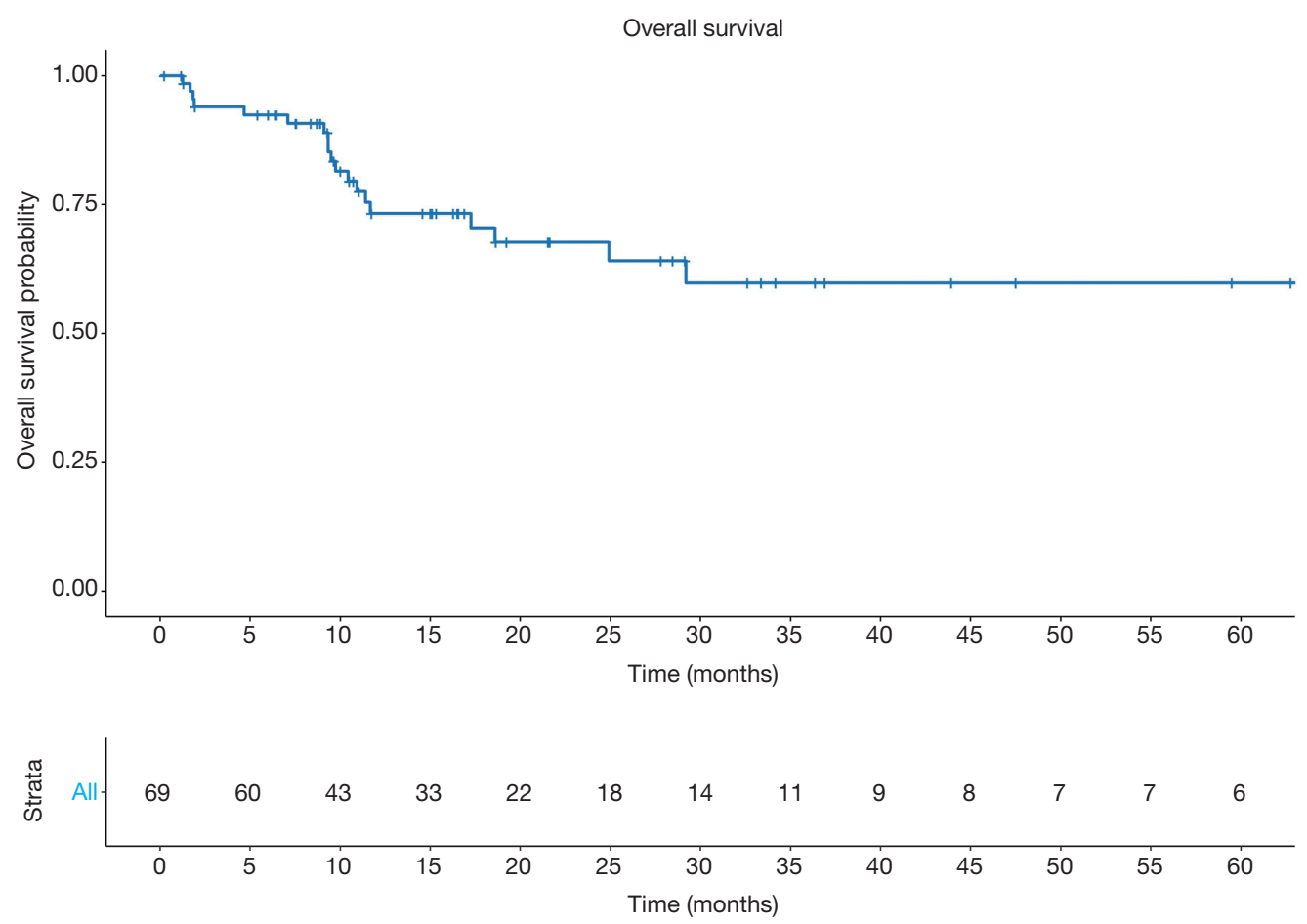

Figure 2 Overall survival in the study population.

their manuscript assessed the PC specific survival (PCSS) following conservative penile sparing surgery (PSS) and more aggressive surgery ranged from partial penectomy to radical and total penectomy in a population of 699 patients with PC stage pT1 (18), isolated from a total number of 1,292 patients with penile malignancies. In the 699 pT1 subgroup, $265(37.9 \%)$ patients underwent local tumor excision (LTE) while the remaining 434 (62.1\%) was offered the more aggressive partial/total penectomy. The overall cancer mortality (OCM) resulting in the subgroup of patients treated with an aggressive approach was $40.7 \%$ with a PC specific mortality (PCSM) of $11.7 \%$, numbers not far from our results. In the study published by Patel et al. (26), the author analyzed 220 cases of Australian patients diagnosed with PC, extrapolating data from a large database, the Central Cancer Registry, from 2001 to 2009, also comparing the low volume centers of surgical procedures for PC, with more experienced centers and greater number of surgical interventions on this pathology. On the sample of the 220 patients, Radical penile procedures (partial or total penectomy) were performed in $70 \%$ of the cases. Manish I. Patel then divided the centers involved in "Teaching" and "Non-teaching" centers and low ( $<4$ procedures in 10 years) and high ( $>4$ procedures in 10 years) volume of surgical interventions. The "Non-teaching" hospitals, where almost all were low-volume centers of procedures/year, the number of radical procedures reached and exceeded the percentage of $73 \%$, against $65 \%$ of the structures defined as "Teaching" in a non-statistically significant manner $(\mathrm{P}=0.07)$. Again, in this work, survival in terms of median OS and 5-year OS was assessed, resulting respectively at $86.1 \%$ and $70.6 \%$, significantly higher value than that extrapolated from the study of Zhu et al. but not too far from the percentages obtained in our experience. In the retrospective study by Beech et al. of 2015 (23), the authors published their tenyear experience (2005-2015) on 42 patient PCs and a follow-up of 25 months; passing through the LN staging, the patients were stratified as clinically negative LNs (32 patients- $\mathrm{cN} 0)$ and clinically positive nodes (10 patientscN1). The surgical approach chosen was excisional biopsy in $29 \%$, partial penectomy in $38 \%$ and total penectomy in $33 \%$ of cases. The OS was $60 \%$ in this case at 102 months.

Moreover, there is also the scientific microcosm that orbits this rare neoplasm; guidelines established on this cancer are constructed on a small number and methodologically weak publications result in low evidence level, weak degrees of recommendation and limited adoption of itself. We detected an adherence to the EAU 
guidelines of $71 \%$ for $<\mathrm{T} 2$ stage PC, in a Swedish study (22) and in percentage of $91.4 \%$ in a study that involved more of 6,000 patients, structured in the United States, based on National Comprehensive Cancer Network (NCCN) guidelines for the management of the primary tumor (27). It means we are still treating smaller penile tumors with more radical surgery than necessary.

LN staging and management is undoubtedly an important indicator of survival in PC. EAU guidelines suggest lymphadenectomy or biopsy of sentinel node ( $\mathrm{SN})$ in cN0 with pT1b, T2-T4, and in all case of $\mathrm{cN} 1 / \mathrm{cN} 2$ (28-30). In literature only a low proportion of patients are really treated with LND. Reasons for this should probably due to the high rate of difficulty encountered in the procedural technique combined with the non-negligible mortality and morbidity (31). More recent studies however found an increase in LND rates (31). This is in line with the results of our study which showed a $70 \%$ percentage of approach with LND.

Our findings also have shown agreement with previously published data to consider and define the $\mathrm{N}$ stage as an important survival prognostic indicator, the strongest predictor of poor prognosis. In the Canadian experience of Beech at al. 10 patients presented with clinically palpable nodal disease; 3 were deemed inoperable and the remaining 7 underwent radical lymphadenectomy with 5 patients $\mathrm{pN} 3$ and $2 \mathrm{pN} 0$. In the $\mathrm{pN} 3$ group, 4 died and the last survived 28 months before having a penile recurrence which led to a salvage total penectomy.

For all these reasons we considered the objective of focusing the attention on this setting of patients undergoing radical surgery to be valid and interesting. As for our knowledge of recent literature, this population-based study we presented is the first manuscript entirely focused on radical penectomy patients, extrapolated from a multicenter, international database, which certainly boasts a good number of examined patients.

The study in question certainly shows some limitations. One is certainly the heterogeneity of the PC patient sample in terms of stage, disease progression, surgical skills and learning curves in different phases within the different first surgeons involved in the procedures. However, this in relation to the character and multicentric print of the work that has enlisted 13 centers between Europe and America. The numeric sample of patients (analyzed retrospectively) may seem low but it is in our opinion valid considering the rarity of the tumor pathology of the PC. We have retrospectively considered only patients with the anatomo- pathological squamous cell histotype (SCC), which however appear to be the most frequent histotype in patients with PC. We found systemic recurrences in 14 patients (19.4\%) but unfortunately, we don't know where exactly systemic recurrences were found.

The importance of this study is twofold: on the one hand there is an objective confirmation of high mortality and recurrence of the disease despite a cruel and radical approach even to the minor stage neoplasia, on the other this puts in the spotlight the gap, still important between the various and numerous scientific evidence, the attractive and publicized "mini invasive" or OSS techniques and the actual practice of urological surgical centers, where radical intervention represents a therapeutic option over-used even outside the boundaries of the guidelines.

\section{Conclusions}

These findings of our multi-institutional experience confirm the poor prognosis and the aggressive pattern of this cancer in line with the data currently in the literature, also with a radical penectomy approach. Our data have shown that at 5 years, more than a third of patients do not survive and more than $60 \%$ report a disease recurrence, despite radical treatment and lymphadenectomy approach (that was carried out in more than $70 \%$ of patients). Furthermore, our data have highlighted and demonstrated that, to date, OSS techniques are more an attraction, a surgical mirage but not a real practical reality.

\section{Acknowledgments}

The data used in the study are derived from an international multicenter database (Penile Cancer Adherence study, PECAD Study database) following approval by the local ethical committees.

Funding: None.

\section{Footnote}

Conflicts of Interest: All authors have completed the ICMJE uniform disclosure form (available at http://dx.doi. org/10.21037/tau.2020.04.04). The authors have no conflicts of interest to declare.

Etbical Statement: The authors are accountable for all aspects of the work in ensuring that questions related to the accuracy or integrity of any part of the work are 
appropriately investigated and resolved. This study was approved by the local ethical committees (No. CE Ch/Pe 01/26.01.17).

Open Access Statement: This is an Open Access article distributed in accordance with the Creative Commons Attribution-NonCommercial-NoDerivs 4.0 International License (CC BY-NC-ND 4.0), which permits the noncommercial replication and distribution of the article with the strict proviso that no changes or edits are made and the original work is properly cited (including links to both the formal publication through the relevant DOI and the license). See: https://creativecommons.org/licenses/by-nc-nd/4.0/.

\section{References}

1. Douglawi A, Masterson TA. Updates on the epidemiology and risk factors for penile cancer. Transl Androl Urol 2017;6:785-90.

2. Barnholtz-Sloan JS, Maldonado JL, Pow-sang J, et al. Incidence trends in primary malignant penile cancer. Urol Oncol 2007;25:361-7.

3. Christodoulidou M, Sahdev V, Houssein S, et al. Epidemiology of penile cancer. Curr Probl Cancer 2015;39:126-36.

4. Siegel RL, Miller KD, Jemal A. Cancer statistics, 2019. CA Cancer J Clin 2019;69:7-34.

5. Rippentrop JM, Joslyn SA, Konety BR. Squamous cell carcinoma of the penis: evaluation of data from the Surveillance, Epidemiology, and End Results program. Cancer 2004;101:1357-63.

6. Marchioni M, Berardinelli F, De Nunzio C, et al. New insight in penile cancer. Minerva Urol Nefrol 2018;70:559-69.

7. Parkin DM, Ferlay J, Curado MP, et al. Fifty years of cancer incidence: CI5 I-IX. Int J Cancer 2010;127:2918-27.

8. Sosnowski R, Kulpa M, Kosowicz M, et al. Quality of life in penile carcinoma patients - post-total penectomy. Cent European J Urol 2016;69:204-11.

9. Maddineni SB, Lau MM, Sangar VK. Identifying the needs of penile cancer sufferers: a systematic review of the quality of life, psychosexual and psychosocial literature in penile cancer. BMC Urol 2009;9:8.

10. Aaronson NK, Ahmedzai S, Bergman B, et al. The European Organization for Research and Treatment of Cancer QLQ-C30: a quality-of-life instrument for use in international clinical trials in oncology. J Natl Cancer Inst 1993;85:365-76.
11. Hakenberg OW, Compérat EM, Minhas S, et al. EAU guidelines on penile cancer: 2014 update. Eur Urol 2015;67:142-50.

12. Clark PE, Spiess PE, Agarwal N, et al. Penile cancer: clinical practice guidelines in oncology. J Natl Compr Canc Netw 2013;11:594-615.

13. Scarberry K, Angermeier KW, Montague D, et al. Outcomes for Organ-Preserving Surgery for Penile Cancer. Sex Med 2015;3:62-6.

14. Lont AP, Gallee MP, Meinhardt W, et al. Penis Conserving Treatment for T1 and T2 Penile Carcinoma: Clinical Implications of a Local Recurrence. J Urol 2006;176:57580; discussion 580.

15. Djajadiningrat RS, van Werkhoven E, Meinhardt W et al. Penile sparing surgery for penile cancer-does it affect survival? J Urol 2014;192:120-5.

16. Philippou $\mathrm{P}$, Shabbir M, Malone $\mathrm{P}$ et al. Conservative surgery for squamous cell carcinoma of the penis: resection margins and long-term oncological control. J Urol 2012;188:803-8.

17. Martins FE, Rodrigues RN, Lopes TM. Organ-preserving surgery for penile carcinoma. Adv Urol 2008:634216. doi: $10.1155 / 2008 / 634216$.

18. Zhu Y, Gu WJ, Wang HK, et al. Surgical treatment of primary disease for penile squamous cell carcinoma: A Surveillance, Epidemiology, and End Results database analysis. Oncol Lett 2015;10:85-92.

19. O'Kane HF, Pahuja A, Ho KJ, et al. Outcome of glansectomy and skin grafting in the management of penile cancer. Adv Urol 2011;2011:240824.

20. Mossanen M, Holt S, Gore JL, et al. 15 Years of penile cancer management in the United States: An analysis of the use of partial penectomy for localized disease and chemotherapy in the metastatic setting. Urol Oncol 2016;34:530.e1-530.e7.

21. Chipollini J, Tang DH, Sharma P, et al. National Trends and Predictors of Organ-sparing for Invasive Penile Tumors: Expanding the Therapeutic Window. Clin Genitourin Cancer 2018;16:e383-9.

22. Kirrander P, Sherif A, Friedrich B, et al. Swedish National Penile Cancer Register: incidence, tumour characteristics, management and survival. BJU Int 2016;117:287-92.

23. Beech B, Izawa J, Pautler S, et al. Penile cancer: Perspective from a Canadian tertiary care centre. Can Urol Assoc J 2015;9:315-9.

24. Moses KA, Winer A, Sfakianos JP, et al. Contemporary management of penile cancer: greater than 15 year MSKCC experience. Can J Urol 2014;21:7201-6. 
25. Dorff TB, Ballas LK, Schuckman AK. Current Management Strategy for Penile Cancer and Future Directions. Curr Oncol Rep 2017;19:54.

26. Patel MI, Yuminaga Y, Bang A, et al. Volume-outcome relationship in penile cancer treatment: a population based patterns of care and outcomes study from Australia. BJU Int 2016;118 Suppl 3:35-42.

27. Campbell RA, Slopnick EA, Ferry EK, et al. Disparity between pre-existing management of penile cancer and NCC guidelines. Urol Oncol 2017;35:531.e9-531.e14.

28. da Costa WH, Rosa de Oliveira RA, Santana TB, et al. Prognostic factors in patients with penile carcinoma and

Cite this article as: Ghahhari $\mathrm{J}$, Marchioni M, Spiess PE, Chipollini JJ, Nyirády P, Varga J, Ditonno P, Boccasile S, Primiceri G, De Nunzio C, Tema G, Tubaro A, Veccia A, Antonelli A, Musi G, De Cobelli O, Conti A, Puliatti S, Micali S, Álvarez-Maestro M, Quesada Olarte J, Diogenes E, Lima MVA, Tracey A, Guruli G, Autorino R, Sountoulides P, Sosnowski R, Schips L, Cindolo L. Radical penectomy, a compromise for life: results from the PECAD study. Transl Androl Urol 2020;9(3):1306-1313. doi:10.21037/tau.2020.04.04 inguinal lymph node metastasis. Int J Urol 2015;22:669-73.

29. Zargar-Shoshtari K, Sharma P, Djajadiningrat R, et al. Extent of pelvic lymph node dissection in penile cancer may impact survival. World J Urol 2016;34:353-9.

30. Zhu Y, Gu CY, Ye DW. Population-based assessment of the number of lymph nodes removed in the treatment of penile squamous cell carcinoma. Urol Int 2014;92:186-93.

31. Thuret R, Sun M, Lughezzani G, et al. A Contemporary Population-Based Assessment of the Rate of Lymph Node Dissection for Penile Carcinoma. Ann Surg Oncol 2011;18:439-46. 